\title{
PISTAS BIOGRÁFICAS DE HENRIQUETA MARTINS CATHARINO E A COLEÇÃO DE ARTE POPULAR DO INSTITUTO FEMININO DA BAHIA
}

\section{SUELY MORAES CERÁVOLO}

https://orcid.org/0000-0002-3898-8769

Universidade Federal da Bahia

RESUMO No encalço da biografia colecionista de Henriqueta Catharino, que criou e levou adiante o Instituto Feminino da Bahia (IFB, Salvador), instituição privada dirigida pela Fundação do Instituto Feminino da Bahia (FIFB) priorizamos a formação do Museu de Arte Popular dentre os segmentos museológicos que abriga. A metodologia amparou-se nos recortes de jornais, documentação arquivada no álbum Recordando do IFB (dos anos 1920 até final dos 1960), possibilitando observar a formação e deslocamento paulatino de coleções para compor museus, e os discursos institucionais situando o "artista anônimo". Conclui-se que a manifestação colecionista de Henriqueta Catharino ficou encoberta pelas intenções derivadas da filosofia de vida caritativa concretizada pelos projetos desenvolvidos e posição social de destaque, facilitando o trânsito entre dois mundos separados pela ocupação de espaços sociais distintos (o da elite e o dos artesãos).

Palavras-chave: Biografia colecionista. Henriqueta Catharino. Instituto Feminino da Bahia.

\section{ABSTRACT CLUES FROM THE BIOGRAPHY OF HENRIQUETA MARTINS CATHARINO AND THE POPULAR ART COLLECTION OF THE BAHIA WOMEN'S INSTITUTE}

Based on the biography of the collector Henriqueta Catharino, who founded and led the Bahia Women's Institute (IFB, Salvador), a private institution subordinate to the Bahia Women's Institute Foundation (FIFB), we prioritized the establishment of the Popular Art Museum, among the museological themes housed there. The methodology focused on newspaper clippings and documentation stored in the IFB's Recordando archive, from the 1920s to the end of the 1960s. This made it possible to observe the formation and gradual evolu- 
tion of the collections used to create museums, and the institutional discourse empowering the "anonymous artist." It was concluded that Henriqueta Catharino's collector tendencies were camouflaged by the characteristics of a charitable lifestyle and manifested in the projects she developed and her elevated social position, which allowed her to move freely between two worlds, pertaining to different social spaces, that of the elite and that of the artisans.

Keywords: Collector biography. Henriqueta Catharino. Bahia Women's Institute.

\section{RESUMEN PISTAS BIOGRÁFICAS DE HENRIQUETA MARTINS CATHARINO Y LA COLECCIÓN DE ARTE POPULAR DEL INSTITUTO FEMENINO DE BAHIA}

Siguiendo la biografia coleccionista de Henriqueta Catharino, quien creó y llevó a cabo el Instituto Femenino de Bahía (IFB, Salvador), una institución privada dirigida por la Fundación del Instituto Femenino de Bahía (FIFB), priorizamos la formación del Museo de Arte Popular entre los segmentos museológicos que alberga. La metodología fue apoyada por recortes de periódicos, documentación archivada en el álbum Recordando del IFB (de los años 1920 hasta finales de 1960), que permite observar la formación y el desplazamiento gradual de colecciones para componer museos, y discursos institucionales que ubican al "artista anónimo". Se puede concluir que la manifestación coleccionista de Henriqueta Catharino quedó oculta por las intenciones derivadas de la filosofía caritativa que ejercía en los proyectos y su destacada posición social, que facilitaba el tránsito entre dos mundos separados por la ocupación de espacios sociales distintos (el dla élite y de los artesanos).

Palabras clave: Biografía coleccionista. Henriqueta Catharino. Instituto Femenino de Bahía.

\section{À procura de indícios}

Pela via da formação de uma coleção que se transformou em Museu de Arte Popular do Instituto Feminino da Bahia (IFB), instituição privada dirigida pela Fundação do Instituto Feminino da Bahia (FIFB), procuramos indícios da biografia colecionista da personagem que criou e dirigiu esta escola feminina na cidade do Salvador: Henriqueta Martins Catharino. Personalidade que chega a ser enigmática, embora enaltecida pelos trabalhos que realizou, filha de rico industrial de têxteis, nascida em Feira de Santana (Estado da Bahia, 1886)', conduziu projetos assistencialistas e educati-

1 Filha de Bernardo Catharino, português, casado com Úrsula Martins Catharino. Sobre sua biografia têm-se o texto, escrito um ano após seu falecimento (21 de junho de 1969), por Marieta Alves (2003), secretaria do IFB e braço direito de Henriqueta; o perfil de educadora por Elizete Passos (2010). 
vos a partir da década de 1920. Ao longo de sua vida conviveu com diferentes regimes políticos, alternâncias entre crises e desenvolvimento econômico, transformações urbanas na capital baiana, além de distintas angulações culturais. Nesse cenário mutante, guiada pela moral cristã de cunho conservador, promoveu a beneficência e a profissionalização da mulher, com pleno apoio da igreja católica (PASSOS, 1993; 2010). De acordo, aliás, com os propósitos de associações de senhoras católicas, inclusive na Bahia, nas primeiras décadas do século XX (VIEIRA, 2015). 0 apreço por arte, música e poesia relacionadas ao sagrado e ao Romantismo nutriu-se de viagens à Europa, particularmente à França, de lá trazendo objetos de arte e curiosidades (QUEIRÓZ, 2014; 2016).

O Museu de Arte Popular integra os segmentos museológicos do IFB (outros: Museu Henriqueta Catharino; Museu do Traje e Têxtil). Composto por volume considerável de exemplares encontra-se separado, no presente, por figuração, a exemplo do conjunto de bonecas, ou por material (cerâmica, madeira, osso, metais, cestaria etc.) com artefatos do Brasil (Nordeste brasileiro e Recôncavo Baiano) e do exterior (QUEIRÓZ, 2016). o linear arranjo expográfico ocupa estantes de parede, vitrines, armários, arcas e outros expositores, com destaque para o diorama de cozinha e fogão à lenha e apetrechos, ladeados pela figura em pano de uma negra em vestes singelas e torço na cabeça. Em ângulo museológico trata-se de objetos que perderam a "utilidade canônica" aproximados na construção expositiva, porém, nem sempre chegados uns aos outros no cotidiano. Esse deslocamento dá lugar à "gramática manipulada por terceiros" (BRITTO, 2018, p. 21). Ou seja, os objetos constitutivos de museus são articulados e emoldurados de significados nas exposições museológicas a partir de diretrizes que determinam a narração e as mensagens e, nessa dinâmica, concretizam a sutil circularidade da produção e a reprodução do social usando estratégias que ultrapassam as coisas propriamente ditas (MENESES, 1994; CUNHA, 2006). Pode-se afirmar que há intenções na base das escolhas do colecionista que, para reunir coisas isoladas ou em conjunto se apoia na relação consigo mesmo, nos vínculos sociais que mantém e na projeção social que constrói para si, indicando, para o observador, variáveis pragmáticas e simbólicas (COUTINHO, 2018). A associação de tais ponderações orienta o analista para apreender possiveis elementos descritivos e interpretativos dando corpo à historiografia colecionista propriamente museológica.

O tema da cultura popular é complexo, a começar pela própria concepção sujeita a formulações distintas entre cientistas sociais, e não menos intrincado ao lidar com os processos de formação de coleções museológicas de motivos nem sempre explícitos. Necessário ressaltar que o colecionismo da arte popular no Brasil e outros países da América Latina foi ativado por colecionadores particulares e públicos, valorizando-a e the dando legitimidade artística, acendendo o interesse dos Estados por bens culturais para servir de modelos estéticos e simbólicos (SANTOS, 2015). Com efeito, o popular sob o prisma da arte e desta com o folclore, relacionados à tradição ou a vida tradicional, vista em declínio por causa da industrialização, há muito aportaram fins nacionalizantes ${ }^{2}$, perspectiva que corrobora

2 No Brasil, de 1930 a 1950 foram criadas instituições, políticas culturais públicas, o mercado cultural incorporando manifestações e expressões artístico-populares chamando a atenção ao sertão nordestino, compondo a "pedagogia nacional" circunscrevendo o ser brasileiro (ALVES, 2013, p.134-144; grifo nosso). As culturas negras tomadas como tradições inalteradas ocuparam igualmente a esfera cultural sob a influência de literatos, músicos, artistas modernos e fotógrafos detentores do campo de produção simbólico ressoando nos meios de comunicação. Os guias turísticos dos anos 1950 reforçaram essa imagem indicando o que conhecer e visitar na Bahia invertendo a condição de exclusão do negro para a de protagonista da autêntica cultura baiana, que se tornou interessante para a indústria do turismo (ROMO, 2018). 
com Marijara S. Queiróz (2016) ao afirmar que o material popular no IFB não foi isolado nem no Brasil ou no exterior. Além disso, o fato de Henriqueta Catharino, pessoa preparada (com domínio de outros idiomas como alemão, francês e inglês ${ }^{3}$ ), culta e viajada, nos abre a possibilidade de contato com o que acontecia no exterior, caso das exposições universais amplamente divulgadas nas rodas da elite, ou de arte que aconteciam, por exemplo, na França.

Não é o caso aqui de inventariar as coleções de cultura material do popular em nosso país, todavia, no intuito para melhor situar o contexto delimitado à Bahia, citamos: a Coleção Sertaneja formada pelo naturalista Edgar Roquette-Pinto (diretor do Museu Nacional de 1926-1931), partícipe da Comissão Rondon, depois Coleção Regional, na gestão de Heloisa Alberto Torres (1938 a 1955), que excursionou pela Bahia em 1940 percorrendo terreiros de Candomblé na cidade do Salvador e comprou peças em feiras livres e, em outra viagem em 1950, visitou o Museu do Estado e o Instituto Feminino pelo interesse em estudar trajes dos Orixás (DIAS, 2005, p. 153). Por Mário de Andrade a coleção particular que leva seu nome, derivada das "viagens etnográficas" para o Norte e Nordeste (1928-1929), preocupado com estético, o etnográfico e o documental criou curso preparatório de folcloristas para trabalho de campo no Departamento de Cultura do Estado de São Paulo (1936-1939), e fundou a Sociedade de Etnografia e Folclore (1937) para realizar pesquisas (LOPES, 1972; SOARES, 1983) ${ }^{4}$.

3 Fraulein Louise Von Schiller foi preceptora de Henriqueta Catharino. Marieta Alves encontra na instrutora a explicação para a "polidez de seu trato social, consolidada e aperfeiçoada nas proveitosas viagens que fez à Europa". Nesse trecho biográfico pode-se ver a fotografia de Henriqueta e família no souvenir de Montreaux (Suiça) (ALVES, 2003, p. 17-20).

4 Sobre a coleção Mario de Andrade consultar: Coleção Mário de Andrade: Religião e Magia, Música e Dança, Cotidiano. (org. Marta Rossetti Batista). São Paulo: Editora da Universidade de São Paulo: Imprensa Oficial do Estado de São Paulo, 2004. Para a atuação em pesquisa: Mário de Andrade e a Sociedade de Etnografia e Folclore. Departamento de Cultura da Prefeitura do Município de São Paulo1936-1939. Rio de Janeiro: FUNARTE, Instituto Nacional de Folclore; São Paulo: Secretaria Municipal de Cultura, 1983.
Outros conjuntos se formaram por intelectuais dedicados à pesquisa além do eixo Rio-São Paulo ${ }^{5}$ e, na Bahia, Gastão de Bettencourt (1957, p. 189), musicógrafo e folclorista português, referese à existência de "Pequeno Centro de Estudos Folclóricos", em Salvador, que teria durado de 1940 a 1945.

O colecionismo de Henriqueta Catharino ${ }^{6}$ não seguiu o caminho da coleta em campo para pesquisas. Resultado de escolhas e acumulação, estruturou-se em outras bases. Pelo estudo de Elizete Passos (1993, p. 32-33) a intenção era complementar a formação das alunas sobre os costumes e usos nos espaços domésticos e sociais da aristocracia da Bahia, contando com doações de famílias importantes da cidade de Salvador e da região, confiantes que ali estava o "lugar apropriado e seguro para guardarem suas relíquias" e, para o Museu de Arte Popular o representativo da cultura nacional e, em particular, da cultura baiana. Em chave antropológica os dois posicionamentos apontam para o uso da cultura material demarcando discursos de alteridade ao tempo em que estabelecem o vínculo identitário com a Bahia e desta com o país. Com efeito, o IFB conquistou projeção. Tornou-se emblema da Bahia muito bem posicionado na rede de sociabilidade de elite - pessoas da sociedade, autoridades, clero e alunas - e admirado pela forma como conduzia os trabalhos e

5 Cita-se em Sergipe a coleção formada pelo pesquisador sergipano José Augusto Garcez, criador de Museu Sergipano de Arte e Tradição em Aracaju (1948); na mesma cidade, o Museu Regional de Folclore (1952), graças ao trabalho do etnógrafo e pesquisador Felte Bezerra (SOUZA, 2019); Alagoas: Théo Brandão, intelectual que participou ativamente da criação da Comissão Nacional de Folclore (1947) e estruturação da Campanha de Defesa do Folclore Brasileiro (1958), dedicou-se aos folguedos, efetuou registros fotográficos e sonoros, formou coleção particular depois acervo do museu da Universidade Federal de Alagoas, em 1972 (CHAVES, 2012).

6 Sobre o colecionismo de Henriqueta Catharino citase: Marijara Queiróz (2016; 2014); as roupas brancas do Museu do Traje e do Têxtil: (OLIVEIRA, 2009); exposição das roupas de mulheres negras (FLORES, 2017); paramentos litúrgicos (VALE, 2017). 
serviços prestados à sociedade (PASSOS, 1993). Voltando a atenção para a cidade do Salvador conta-se com notícias sobre museus e coleções em Guy de Hollanda (1958), compilador do repertório produzido para a Organização Nacional do Conselho Internacional de Museus (ONICOM), vinculada ao Conselho Internacional de Museus (ICOM), com informações das próprias instituições. Desta publicação consta, em relação à Bahia: a Coleção Nelson de Oliveira (particular e eclética), o Museu de Arte Sacra da Catedral Basílica, o Museu do Estado, o do Instituto Geográfico e Histórico da Bahia (IGHB), do Instituto Nina Rodrigues e do Instituto Feminino com dois segmentos - o de Arte Antiga e o de Arte Popular -, ambos na categoria de museu particular mantido pela $\mathrm{FIFB}^{7}$. A finalidade apontada para o Museu de Arte Antiga era “[...] conservar o que fez ou possuiu a mulher bahiana no passado, mas as doações recebidas fizeram que o seu acêrvo inclu[isse] também importantes peças de arte brasileira" (HOLLANDA, 1958, p. 68), com sala de exposições em área de $11.60 \mathrm{~m}$ por $15.50 \mathrm{~m}$, móveis e objetos de arte ornando os "lugares adequados" por toda a edificação (p. 68). E a de Arte Popular “[...] incentivar e preservar a arte popular, tornando-a conhecida das alunas do Instituto Feminino e do público em geral" (HOLLANDA, 1958, p. 71) com artefatos de cestaria, trançados, cerâmica, tecelagem, armas, peças indígenas, artesanato feminino e uma significativa coleção de joias de ouro e prata, e a indumentária da negra baiana.

Não obstante o Museu do Estado faça constar do acervo a arte colonial baiana e a estrangeira, mobiliário, prataria etc., incluiu a "arte

7 Os dois museus integravam a Divisão de Cultura do IF, então composta por: Biblioteca, Museu de Arte Antiga, Museu de Arte Popular, Escola Técnica de Comércio e Ginásio Feminino da Bahia, Cursos Diversos e Museu de História Natural; mantidos pelo orçamento do Instituto, sem pessoal próprio. Quanto ao folclore contava com a colaboração de interessados no assunto: o estudioso da cerâmica popular Carlos José da Costa Pereira, autor de A cerâmica popular da Bahia (1957), e Albano Oliveira. primitiva (universal), arte popular (regional) e arte moderna (brasileira)", frisando que expunha somente parte das coleções. 0 museu do IGHB, além do conjunto de história natural, a seção de geografia e história (indumentária, numismática, armaria, arqueologia e etnologia), a de folclore, com subsecção afro-brasileira. 0 Instituto Nina Rodrigues, as seções de criminologia, medicina legal, antropologia com peças do "cangaceirisimo" e "mitos afro-brasileiros" com destaque para orixás africanos e baianos (HOLLANDA, 1958, p. 72-75; 76-77; grifos do texto). Não parece coincidência que os museus de Salvador rendessem tributos ao popular e ao folclore em publicação que saiu um ano depois do III Congresso Nacional de Folclore em 1957, em década em que o tema ocupava a ordem do dia no panorama intelectual e das ciências sociais no Brasil (VILHENA, 1997). Note-se que até então ${ }^{8}$ sob a rubrica específica - Museu de Arte Popular - somente o Instituto Feminino dispunha de conjunto direcionado e, além disso, nesse período, com espaço físico definido para apresentação, aspecto comentado adiante. Significativo assinalar que o Museu de Arte Popular integrou igualmente o evento do III Congresso Nacional de Turismo, realizado em Salvador em 1955.

Ao privilegiar o Museu de Arte Popular do IFB procuramos desenredar, através de notícias em jornais, a trajetória intrincada de uma coleção que tomou grandes proporções e, nesse roteiro, pinçar a paixão colecionista de Henriqueta Catharino, fator que, a nosso ver, não é menor em sua biografia.

\section{Exposições e museus ou reflexos do colecionamento de Henriqueta Catharino}

Uma questão em suspenso recai sobre o engendramento do museu de artesania popular

8 Lina Bo Bardi concebe o Museu de Arte Popular (Solar do Unhão, Salvador), em novembro de 1963, com a exposição Nordeste (PEREIRA, 2001). 
no IFB, instigando acompanhar os rumos da coleção pela posição de Henriqueta Catahrino e da instituição, considerando-se que, como ocorre em geral com qualquer outra coleção, as escolhas determinam a valoração atribuída e incorporam aspectos individuais, históricos e culturais dando sentido ao conjunto formado por mais eclético que seja (COSTA, 2007).

A trajetória aqui descrita foi extraída principalmente de recortes de jornais acumulados cuidadosa e cronologicamente desde a década de 1920 aos finais dos anos 1960, no álbum Recordando $^{9}$, e outros documentos referidos ao longo do texto. Em seu aspecto material o álbum foi composto em papel de espessa gramatura, encapado em tecido de algodão cru e na frente e no verso de cada página traz os recortes colados com a indicação manuscrita do periódico e data (dia/mês/ano). Na primeira folha, sobre fundo de papel trabalhado artesanalmente, a etiqueta referendando o IFB e o evocativo título. Duas fotografias legendadas complementam esse quadro inicial assinalando a trajetória (e desenvolvimento) institucional: uma apresenta o "Prédio onde começou o Instituto Feminino da Bahia 1923 a 1926"; a outra, o "Instituto Feminino da Bahia - Av. Sete, 215. Prédio do Patrimônio onde estão reunidas todas as secções" (Figura 1 e 2). Merece comentário o fato de testemunhar as concepções em voga sobre a cultura simultaneamente território do material e do simbólico, de opiniões e juízos. Além disso, por si só indica a intenção de preservar a memória (SILVA, 2008), em um primeiro relance a memória institucional pelos empreendimentos e a receptividade social positiva do trabalho do IFB, mas, nela a figura central: Henriqueta Martins Catharino.

9 Os levantamentos no álbum e outras fontes vincularam-se a projetos e planos de trabalho do PIBIC/ UFBA, cujas consultas ao IFB foram devidamente autorizadas. Em 2013 - Milena de Jesus Santos; 2014 - Jussara Santos Piedade; 2016 - Louise Pereira dos Santos; Silvana Marback Magno Baptista de Almeida Castro 2015, 2016, 2017 e 2018.
Figura 1 - Primeira página do Álbum Recordando.

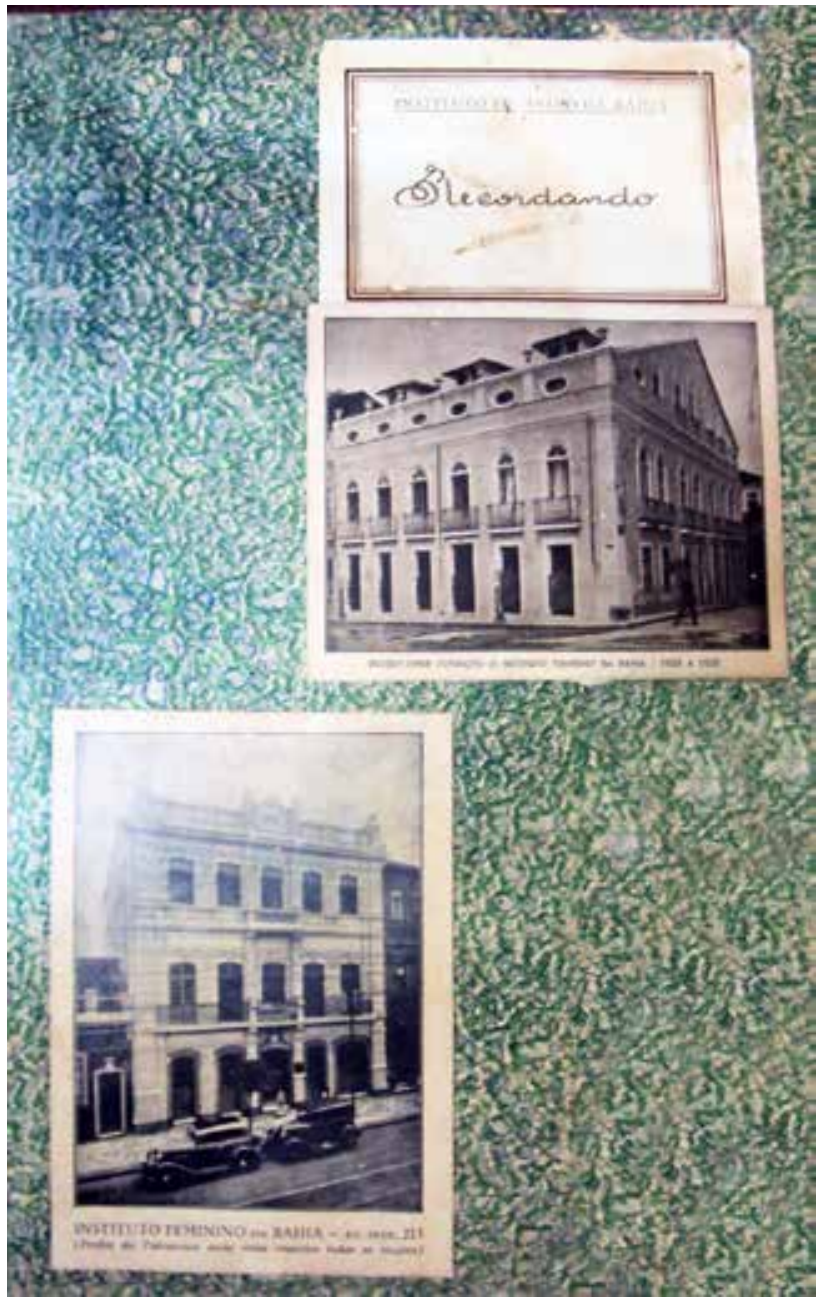

Fotógrafa: Jussara Santos Piedade, 2014/2015.

Figura 2 - Álbum Recordando: Detalhe da fotografia da primeira edificação ocupada pelo IFB ${ }^{10}$.

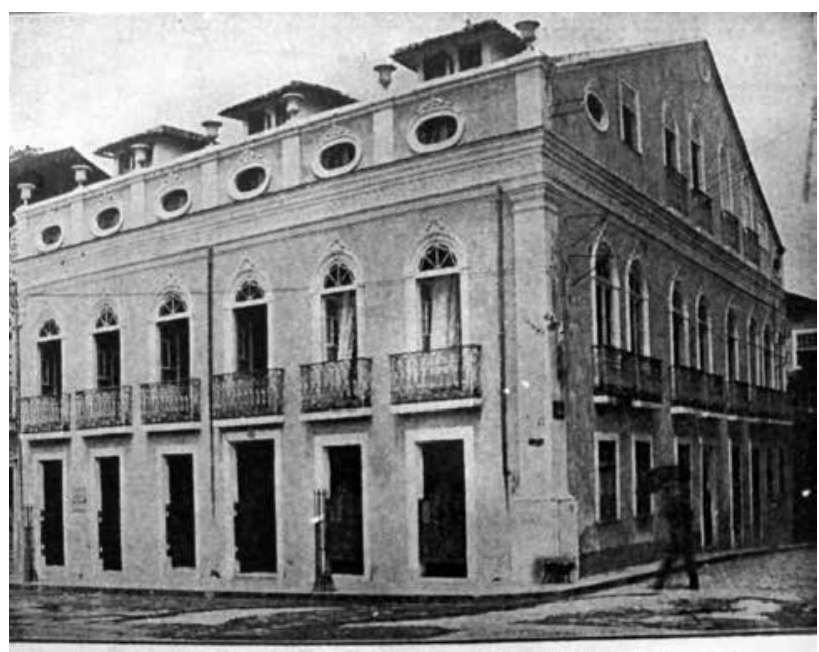

PREDIO ONDE COMEÇOU O INSTITUTO FEMININO DA BAHIA / I923 A 1926

Fotógrafa: Jussara Santos Piedade, 2014/2015.

10 Edificação na qual se iniciaram os trabalhos do IFB 1923-1926. 
O álbum formula a "prática de arquivamento" (BRITTO, 2014) e, mesmo sem autoria ou justamente por isso, constrói a biografia da personalidade pública da diretora trazendo indícios de sua linha de conduta, principalmente em relação ao Instituto, reafirmando a dupla intenção memorialística. Embora formar uma coleção remeta à "história de paixão" cujo cerne se faz nos diálogos do colecionador consigo mesmo (GUTIERREZ, 2012), não há evidências diretas desse sentir de Henriqueta uma vez que, até onde se sabe, não deixou escritos. A isenção declarada em não protagonizar a obra que realizava - os periódicos o fizeram apontando reiteradamente suas virtudes ${ }^{11}$, além de outros meios de comunicação (Figura 3) - decerto não descarta o impulso colecionista e o apreço da diretora do Instituto pelas peças populares (ou outras). Os indicativos "sem alardes" do gosto e a intenção de cultuar as tradições baianas ${ }^{12}$ ficam por conta dos entremeios nos noticiários, em outros escritos contemporâneos ou posteriores.

A leitura do noticiário demonstra que, a autonomia do conjunto do popular, resultou do deslocamento paulatino da inicial justaposição dos trabalhos manuais, produzidos por mulheres das obras assistenciais e alunas (apresentados em eventos abertos ao público com fins de venda $)^{13}$, com as peças executadas por outras artesãs (ou artesãos). A questão do espaço é outro fator que parece interferiu quer na justaposição quer no deslocamento, observáveis na articulação das atividades desenvolvidas em nome do IFB.

11 Henriqueta evitava receber elogios e chamar a atenção (PASSOS, 2010, p. 21). Exemplo se tem em "Felicitamos o "Diario da Bahia" (09.07.1944), enaltecendo-a pelas ações em prol da formação da mocidade.

12 Exposiçẫo de Arte Antiga. A Tarde, 28.03.1949.

13 Os trabalhos femininos (ou parte deles) destinados à venda eram expostos em Salvador e, em algumas ocasiões antes do envio para a Associação de Senhoras Brasileiras, no Rio de Janeiro da qual o Instituto era congênere, sendo comum a remessa de bonecas, lenços e rendas da Bahia.
Figura 3 - Álbum Recordando: Informe do programa radiofônico em homenagem a Henriqueta Catharino.

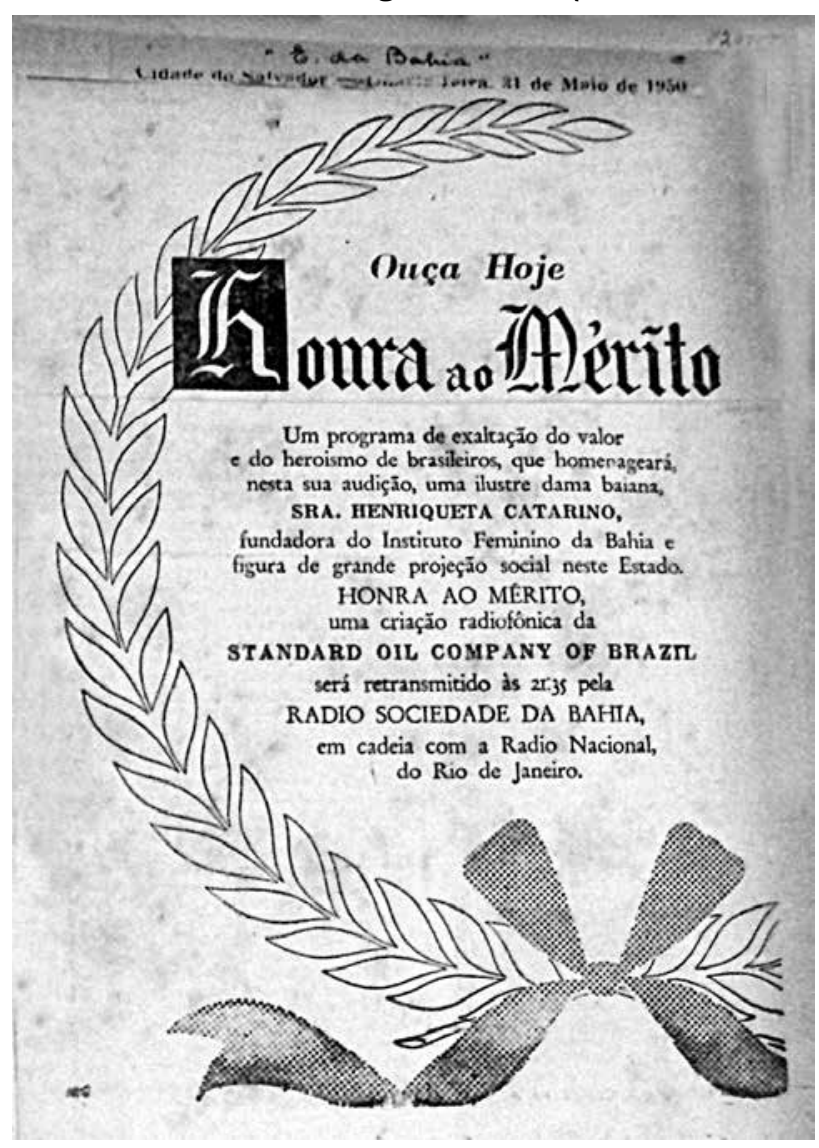

Fotógrafa: Jussara Santos Piedade, 2014/2015.

No que se refere à junção dos trabalhos manuais com as peças da artesania popular os jornais são pródigos em descrições ao divulgar bazares, festas comemorativas e exposições ressaltando o lado artístico da mulher baiana e trabalhos sob a rubrica Arte - prendas domésticas, trabalhos manuais femininos e culinária -. Nesses momentos misturavam-se recorrentemente os chamados "trabalhos artísticos" desde "crochets finíssimos" a bonecas de pano e madeira entalhada ${ }^{14}$, ou ainda "jóias, leques, vestidos, caixas de trabalhos de agulha, penas, cabelos, conchas, etc."15, indicando-nos a mescla de objetos (exemplo Figura 4).

14 As Victorias do Instituto Feminino. Trabalhos artísticos expostos. A Tarde, 06.08.1932.

15 O Aniversario de uma útil instituição. Exposição de arte e festa de amizade no Instituto Feminino. A Tarde, 01.10.1941. 
Figura 4 - Álbum Recordando: Anúncio de Exposição de Trabalhos, 1931.

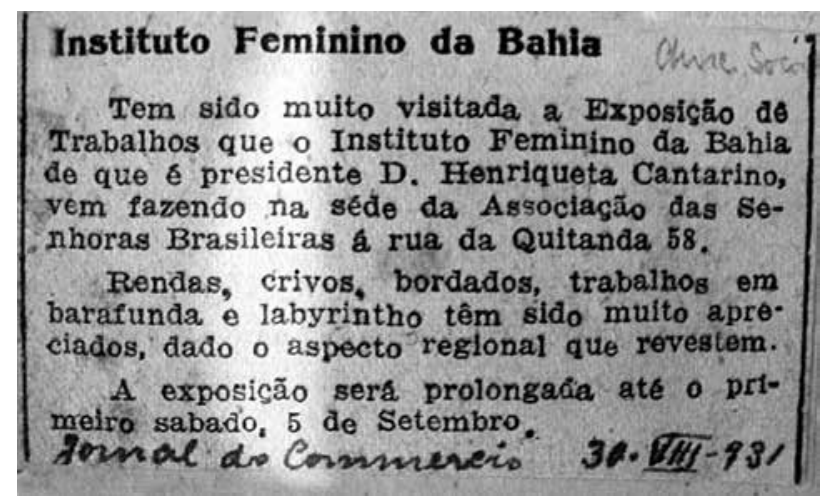

Fotógrafa: Jussara Santos Piedade, 2014/2015.

Em relação ao espaço, desde o começo do trabalho assistencialista e educacional, o IFB mudou de acomodações até se estabelecer na sede própria. Ocupou endereços no Terreiro de Jesus (Pelourinho, 1923), no bairro da Piedade (1926) e deste para o Rosário (até 1939), requerendo adaptação às instalações para os vários projetos que caminhavam paralelamente. Ao desfiar o noticiário observa-se a ocorrência de eventos temporários de trabalhos manuais, e uma parte de exibição fixa, localizada no prédio em ocupação ${ }^{16}$. Com a sede inaugurada em 1939, construída para o Instituto no bairro Politeama, houve condições para juntar, no amplo espaço do subsolo, o material que compôs o Museu de Arte Popular, quando à época dividia a área com as atividades de esportes e lazer (PEIXOTO, 2003, p. 11). Concomitantemente, o mobiliário, a prataria e outras obras do chamado Museu de Arte Antiga integravam os ambientes da escola vistos no cotidiano pelas alunas (PASSOS, 1993; PEIXOTO, 2003) e, certamente, ainda que não citado, por quem ali trabalhava ou transitava. A abertura das coleções privadas do IFB para o público se deu através de muitas exposições temporárias com temas

16 Exemplo pode-se ler no O Imparcial de 1932 ao se referir ao museu "digno de menção" O Apostolado do Bem e da Virtude. Como se forma o coração e o espírito da mulher - O Instituto Feminino da Bahia - Seus elogiáveis fins e excelentes programas. O Imparcial, 13(?).06.1932. de interesse ao universo católico e ao feminino explorando, por vezes, uma única tipologia de objeto (lustres, cristais, leques, opalinas, dentre outros (CERÁVOLO, 2016). Parte das peças vinha das mãos da elite, que as emprestava para complementar as exposições do IFB, a maioria mulheres (QUEIRÓZ, 2016), e parte das próprias coleções do Instituto formadas por Henriqueta, que participava de feiras e leilões (FLORES, 2017, p. 101). Não é de todo estranho pensar que entre os ricos bens e vestidos houvesse coisas mais triviais como se pode confirmar no opúsculo da exposição Belezas do Mar nos Lares da Bahia, ressaltando o apreciar das coisas belas e o requinte da sensibilidade do ser humano por materiais da natureza. No impresso ficou registrado que antigas famílias baianas conservavam trabalhos feitos por conchas pela aceitação do nácar e madrepérola usados em armação para leques, capas de álbuns de retratos ou livros de missa, terços e outras peças (1956) ${ }^{17}$. Indicativo adicional do colecionismo de Henriqueta por peças diferentes constata-se ainda hoje nas legendas de vasos e jarros com flores elaboradas com conchas, expostos na sala adjacente ao saguão de entrada (segmento Museu Henriqueta Catharino), registrando o tipo de peça, material, proveniência, período e a doação da própria diretora $^{18}$. Por volta de 1940 falava-se no Museu de Indústria e Comércio, então em organização ${ }^{19}$.

17 Exposição comemorativa do 33o aniversário IFB. A Tarde, 05.10.1956; Belezas do mar. Exposição anual do Instituto Feminino, A Tarde, 05.10.1956.

18 Do ponto de vista dos procedimentos técnicos museológicos, interessante notar a existência de formulário (datilografado) ao modo de ficha de entrada evidenciando o cuidado em coletar informações sobre as peças que chegavam ao Instituto, registradas, ao que se sabe, em cadernos manuscritos de acesso restrito. Sabe-se de sua existência através das pesquisas realizadas por Oliveira (2009); Queiróz (2014); Vale (2017).

19 Nos 1960 integrava a Divisão de Cultura os museus de Arte Antiga e o Popular e mais o Museu Geológico Econômico (no lugar do Museu de História Natural, nos anos de 1940, também chamado Museu de Ciências Naturais) (Opúsculo Exposições de leques, lenços e luvas. FIFB 5 de outubro de 1964). 
Em empática carta aberta aos baianos "sempre prontos a dar auxilio as iniciativas que tem por fim elevar o nome da Bahia no conceito geral", o IFB solicitava material com o propósito de manter em exposição permanente "produtos naturais do País - minérios, fibras, madeiras, sementes, resinas etc. - mostrando a arte e o engenho do povo", através da "industria típica de cada região" (FIFBA, 1938-1940) ${ }^{20}$. Como seção da "Industria e Commercio" ali se apresentava "amostras de fazendas e photographias das diversas fabricas de tecidos da Bahia" (o pai de Henriqueta fora industrial de têxteis), madeiras, minérios, fibras, raízes e cereais em um museu, cuja parte histórica, voltava-se para objetos de valor ${ }^{21}$. 0 que dá a entender que, talvez por breve momento, foi interesse apresentar produtos da terra como acontecia nas exposições internacionais, nacionais e regionais, objetivo também do museu do IGHB (CERÁVOLO, 2017).

Em outra solicitação - não se tem ao certo a data, provavelmente na mesma década observa-se a concepção flutuante dos museus no IFB. Na justificativa para a reorganização e ampliação do "antigo "Museu de Industria e Comercio"' há indicações para objetos preferenciais para a seção especial "de Arte Popular": "cerâmica, bonecas, objetos de fibra e palha etc". Além de situar a arte popular como seção, o documento ressalta agradecimentos aos brasileiros de quem dependia a grandeza da pátria, e a expectativa que todos colaborassem com "[...] uma pedrinha para a edificação da grande obra do nosso povo" (FIFB, 1938-1940)22. Os pedidos de colaboração eram

20 Carta Aberta aos baianos; Documento datilografado. Comissão formada por Henriqueta Catharino, Edith Argolo Cortizo, Margarida Cruz Vieira. (Fundação do Instituto Feminino da Bahia, Biblioteca Marieta Alves, Dossiê IFB, 1938-1940).

21 Para maior glória de Deus - O "Apostolado Santa Ursula" - Biblioteca - Casa "Santa Ursula" - Museu - Directoria - Conclusão (recorte s/indicação do jornal ou data, Recordando, p. 172)

$22 \mathrm{~s} /$ titulo, documento datilografado, grafado em preto reafirmados, quase uma década depois, para complementarem as mostras temporárias ${ }^{23}$.

Há muitas referências ao Museu de Arte Antiga e, como afirma Eliseo Verón (2004, p. 218), a repetição do mesmo domínio temático gera modalidades de enunciação com ênfases distintas sobre o conteúdo descritivo, fator observável nos textos dos jornais. 0 repórter que visitou em 1941 a exposição antes da abertura ao público com trabalhos "ainda não vendidos", aludindo à metáfora da Bahia como relicário de preciosidades históricas e tarefa civilizadora em preservá-las, viu: "ramalhetes de flores, feitos com penas de aves" elaboradas pelas freiras Ursulinas do Convento da Soledade, mais as esculturas em madeira de Erotides Lopes, executor de trabalhos miniaturizados, possivelmente, do século XVIII24, aspecto apreciado por colecionadores, e gravuras feitas com agulha e cabelos ${ }^{25}$. Parte dos trabalhos em cabelos tornou-se acervo do IFB (QUEIRÓZ, 2014). O Jornal A Tarde descreve a exposição em outro ângulo, porém, destacamos a informação que em 19410 museu começava ${ }^{26}$.

Dessas notícias se extrai que, durante as exposições, formava-se um composto de trabalhos manuais executados por mãos femininas (bonecas, lenços, rendas, outros) junto com objetos relativos à riqueza das senhoras de outrora, com ênfase nos artefatos antigos quando não singulares. Com efeito, pensando-se no contexto restrito à Fundação e ao IFB não parece desprovido de lógica que a dirigen-

(Fundação do Instituto Feminino da Bahia, Biblioteca Marieta Alves, Dossiê IFB, 1938-1940; grifo original).

23 Exposição de louças e porcelanas antigas. A Tarde, 13.07(?).1955.

24 Sobre Erotides Américo de Araújo Lopes. Dicionário Manuel Querino de Arte na Bahia. Disponivel em: http:// www.dicionario.belasartes.ufba.br/wp/verbete/erotides -americo-de-araujo-lopes/. Acesso em: 05 nov. 2019.

25 Faziam flores de penas para viver! Interessantes trabalhos das freiras Ursulinas em tempos dificeis. Esculturas em madeira. O que vimos no museu do Instituto Feminino. Estado da Bahia, 18.08.1941.

26 Uma exposição no Instituto Feminino. A Tarde, 11.10.1941. 
te do Instituto conhecesse, em razão mesmo da sua extensa obra, um contingente de artesãs/artesãos da capital ou interior da Bahia, possibilitando a ampliação dos contatos e ao alcance de uma variedade de objetos por elas/ eles fabricados, fator que deve ter facilitado a aproximação entre as duas camadas sociais: os mais empobrecidos, procurando vender o que produziam, com o segmento mais privilegiado, interessado em comprá-los. Essa proximidade pode ter promovido a aquisição - na forma de presentes recebidos ou compras - das produções de diferentes proveniências colocando-as em relação (e circulação) formando o embrião, inicialmente mesclado, de artes femininas junto com os de arte popular.

A coleção foi crescendo e dentre os motivos o incentivo àquelas produções, assim declarado no repertório de Guy de Hollanda, até compor a linha demarcatória mais definida entre os conjuntos de arte antiga (o que incluía indumentária) e o popular. Procuramos até aqui demonstrar que as exposições temporárias favoreceram a justaposição de tipos de trabalhos entrelaçados pela Arte, e não é demais relembrar que Henriqueta Catharino teve acesso a amplo universo da cultura internacional e nacional até porque, como apontado, trazia peças do exterior ${ }^{27}$.

Entende-se, assim, que conjuntos de artesanias distintas originaram desdobramentos. Os títulos atribuídos ao museu - ou museus - inscritos no noticiário dos jornais o evidenciam nitidamente, segundo o realce do momento (ou da perspectiva e compreensão do jornalista a respeito da estrutura operacional do Instituto). Tem-se: Museu de Arte Antiga Feminina, Museu de Arte Antiga, Museu Regional de Arte Antiga, Museu de Arte, Museu Popular. De todo modo, a estratégia para ampliar as coleções dependeu, como assinalado, da co-

27 Detalhe pertinente nesse aspecto se tem na reprodução do mobiliário expositivo do Museu de Arte Popular de Portugal para o setor do popular do IFB. laboração da sociedade baiana e foi marcante a realização do I Congresso Eucarístico Nacional, quando o IFB organiza Arte e Lavores para apresentar a arte baiana e a vida em sociedade do século XIX, o que deu impulso, segundo Ana Lúcia Uchoa Peixoto (2003) para formar a coleção de indumentária. Na descrição de uma congressista tem-se a organização expositiva separada em salas: em uma, os quadros, imagens antigas, objetos de ouro, uma "preta de pano" ostentando jóias, e noutra "trabalhos de agulhas e arte-feminina" com roupas brancas e bordados, alguns do século XVIII (PEIXOTO, 2003, p. 11).

Em 1938, quando o prédio do Politeama se encontrava em construção (1937-1939), a notícia Museu Regional de Arte Antiga, assinada por J. Berbert Tavares, informava o recebimento, da parte do IFB, do conjunto "pitoresco e original" formado pelo Monsenhor Flaviano Osório Pimentel (falecido em 1933) contendo quadros, trabalhos em conchas, pedras preciosas, adornos e objetos, espécimes da fauna e flora, e a "celebre rêde que servira ao rigoroso escriptor Euclydes da Cunha" e outros mostruários. Essa coleção heterogênea agrupada no mesmo espaço com os trajes femininos usados em festas e bailes para recordar as senhoras e o fausto passado, juntamente com a rede - que não se pode ignorar foi posse (ou assim atribuída) a Euclides da Cunha, autor de Os Sertões, personalidade notável para a historiografia, as ciências sociais e a literatura brasileira -, no dizer de Tavares, caracterizavam a dimensão regional baiana ${ }^{28}$.

Observe-se que a contínua menção ao antigo qualificava o que estivesse sob a chancela da Arte correspondendo, nas entrelinhas, à manutenção de costumes transmutados em tradições aos olhos daquele ramo da elite. Para Carolyn Dean (2006), o uso do termo 'arte' implica em julgamento de valor e na na-

28 O Imparcial, 24.09.1938. 
turalização de fronteiras culturais e históricas. Trata-se de ponderar aqui que as dimensões arte e popular - confluíram no IFB, conjugando o fazer técnico (téchne) com o rudimentar e o vendido em feiras e mercados, segundo as próprias vozes da instituição. Condição fortificada pela intenção do IFB de incentivar a produção do popular, que diz do ajudar, e a de preservar, que diz da continuidade, voltando-se à compilação de Guy Hollanda. Estão aí as intenções implícitas demarcando fronteiras sociais e a quase imperceptível paixão colecionista aceita pelo social, dotada de regras manobradas pelo indivíduo e expressas no "gosto" (COSTA, 2007), neste caso, de Henriqueta Catharino.

\section{O Museu Miscelânea do IFB}

\section{e o Museu de Arte Popular. A referência ao popular: o artista "obscuro"}

Marieta Alves, secretária do IFB, autora de obras sobre Arte brasileira colonial no texto Museu de Arte Popular do Instituto Feminino da Bahia para o 1o Congresso Nacional de Museus, realizado em julho de 1956, em Ouro Preto ${ }^{29}$, complementa o apresentado até aqui sobre a coleção e o Museu de Arte Popular. Traço reiterado é o propósito evocado dos jornais ${ }^{30}$ de "conservar o que fez ou possuiu a mulher bahiana no passado". Bastante reveladora é a expressão - Museu Miscelânia - usada para retomar os primórdios da formação das coleções e referindo a presença de objetos de arte popular, "oferecidos e adquiridos", de igual valor aos olhos dos fundadores do Instituto. Em jogo dicotômico que não passa despercebido

29 Datilografado com nota explicativa no final "Trabalho escrito por D. Marieta Alves, historiadora e 1a. secretária do IFB. Data: 18/09/1959." Arquivo do IFB.

30 No rol noticioso entram o Diario de Noticias, de 1931; O Imparcial, de 1932, o de 1933, quando do I Congresso Eucarístico Nacional pelo jornal Nova Era, e, novamente, O Imparcial, de 1938, além de outros informes divulgados. a autora refere-se aos registros de entrada: os de arte popular junto a outros de "fino quilate artístico". Nesse - uns finos, outros nem tanto - pode-se ler a divisão social dos objetos e de quem os fez. Desse documento, seguindo em ordem cronológica as notícias dos jornais, retemos aspectos sobre a ampliação da coleção, as peças e o popular.

$\mathrm{Na}$ exposição de trabalhos manuais realizada por senhoras da sociedade no Rio de Janeiro, as bonecas e caixinhas de madeira procediam de Santo Estevão do Jacuípe, adquiridas pelo IFB, as esculturas "tipicamente populares" executadas por Ana e Olegária de Almeida, modestas sertanejas que nunca frequentaram Escolas de Belas Artes ${ }^{31}$. 0 cunho regional e a existência de "tudo", apontando o amálgama de objetos são replicados do $O$ Imparcial ${ }^{32}$. Marieta Alves, ao frisar o pitoresco e original, acrescenta que em 1939 o Instituto adquiriu mais peças - bonecas, animais e caixinhas - das duas irmãs sertanejas citadas, acrescendo que o acervo do popular aumentava e exposto em condição provisória ${ }^{33}$. Tem-se, também, o "mais antigo tear manual da Bahia" publicizado pelo Correio da Manhã (15 jul. 1956) e outros jornais (Figura 5), propriedade de Abdias de Sacramento Nobre, homem negro que nele trabalhara doando-o ao IFB ${ }^{34}$, e o tor-

31 Diário de Notícias, 31 jul. 1931 (grifo nosso).

32 O Imparcial, 23 jul. 1932.

33 Sobre as condições provisórias, José Valladares, diretor do Museu do Estado (1938-1959), comentando em Exposições do Congresso de Folclore (1954), observa as quatro exposições organizadas e inauguradas pela comissão local para o evento. Em linguajar que se pode dizer técnico (aspectos estéticos e didáticos) critica na exposição do IFB a falta de etiquetas para os objetos (bons e variados), elogia a conterrânea "abnegada e idealista" (Henriqueta) e a perceptivel presença da mão feminina nos arranjos e diz ali estar o "verdadeiro museu", embora não pronto para ser inaugurado.

34 Quando do Congresso de Turismo, o tecelão foi apresentado como executor dos lindos e coloridos panos da Costa que enfeitavam as autênticas baianas em festas como as do Bonfim ou Conceição. Os panos da Costa das Autênticas Bahianas. As Exposições do Instituto Feminino no C. de Turismo; A Tarde, 10 nov. 1955. $\mathrm{Na}$ foto do jornal Abadias Sacramento Nobre aparece trabalhando no tear. 
no do oleiro Silvestre Costa, de Maragogipinho (município baiano conhecido pelo trabalho em cerâmica) e peças por ele executadas, "as melhores", das quais o IFB possuía exemplares, esclarecendo-nos sobre critérios seletivos de escolha.

Figura 5 - Álbum Recordando: Publicização referente ao Congresso Nacional de Turismo, $1955^{35}$.

\section{Os Panos da Costa das Autênticas Bahianas}

As EXPOSICÓES do I. FEMININO No C. DE

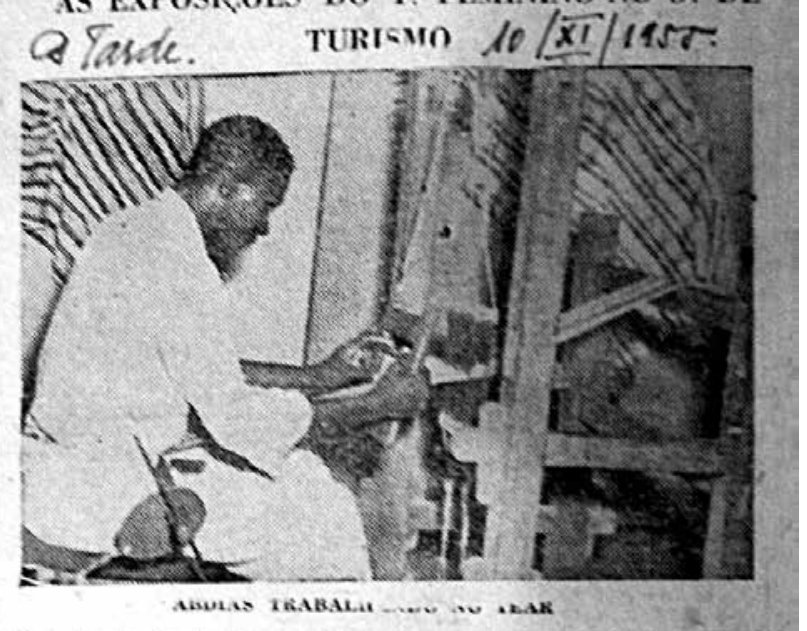

Fotógrafa: Jussara Santos Piedade, 2014/2015.

Dentre as impressões de visitantes comentadas por Marieta ${ }^{36}$ ressaltamos o parecer do “capitão R. Almeida" (1954), ou seja, Renato Almeida, personalidade fundamental na luta pela institucionalização dos estudos de folclore no Brasil (VILHENA, 1997), como atestando a qualidade indiscutivel do acervo do IFB. Autor de Um Reduto de Baianidade. Casa de educação, relicário folclorico, uma instituição

350 texto do artigo no Jornal A Tarde enaltece como atrações as exposições de "arte antiga e arte popular" do IFB - "verdadeiro museu de cousas da Bahia". Sobre o tecelão: "Durante vários dias ali trabalhou, no próprio recinto da exposição, o velho operário tecelão Abdias Sacramento Nobre, que tece os mais lindos e coloridos panos da costa que enfeitam as autenticas bahianas que vemos no adro do Bonfim ou nas festas da Conceição. [...]"

36 Olga Obry, jornalista, escritora, dedicada ao teatro de bonecos (Gazeta, SP, 26 fev. 1947); Cid Prado salienta as "peças regionais" (Correio Paulistano, 20 out. 1949); Érico Veríssimo elogia o "Museu Regional" (Estado da Bahia, 5 nov. 1951). que honra e enaltece a Bahia, convida o leitor a acompanhá-lo na andança sala a sala pelo Instituto, a "Pérola da Bahia"37. Conhecedor do universo popular brasileiro, descreve com maior detalhamento as peças do Museu Popular: a "Peixeira e o Aguadeiro da Bahia antiga, trabalhos em cajá, feitos por Erotildes Lopes, zelador do Clube Inglês, já falecido"; as bonecas típicas e seus nomes ("nona genária Dona Elisa, que foi oferecida com trajes de época. Nada quér, Sinhá, Moleque e muitas outras"), e inclui no rol do popular o Candomblé da Bahia. Renato Almeida deixa entrever seu interesse mais pelos costumes e processos do que pelas joias autênticas da boneca preta. Assim, valoriza, em sua descrição, a cozinha em estilo antigo (valoração do passado), a ancestralidade (boneca da preta velha), e o processo (que "rala com a pedra os ingredientes para o acarajé."). É certo que não faltaram as relíquias relacionadas à Independência e o altar de Igreja da Sé na Capela do IFB, todavia, qualifica etnograficamente o exposto.

Em abordagem metodológica para estudos museológicos, a organização da "gramática expositiva" reflete as proposições e a organização intelectual dos agentes, representativas de dimensões culturais de época, gerando construções narrativas mais ou menos próximas ao real ou, então, conjecturadas (BRITTO, 2018). Sob esse enquadramento a divulgação do jornal soteropolitano A Tarde (10 nov. 1955) informa a conjugação de elementos sobre o que foi considerado amostra de arte popular baiana. Nota-se a conformação da estrutura espacial (local e seções), a seleção das coisas (como as joias levadas pelas negras ostentando a riqueza dos senhores proprietários), e a articulação entre eles - quer no texto quer na visualidade - regulando o significado construído pela racionalidade expositiva. Exemplificase: com o artificio do tempo pretensamente in-

37 Diário da Bahia, 16 mar. 1954. 
determinado ("época africana") encobre-se a escravidão, ou seja, o negro, na razão direta da formulação "artistas obscuros que fixaram por vezes genialmente os ritos africanos". Vejamos no contexto da citação:

Amostra de arte popular bahiana, na parte baixa do edifício do Politeama, dividida em secções, parece abranger todas as manifestações dos artistas obscuros que fixaram por vezes genialmente os ritos africanos, as danças e cerâmica, rêdes e instrumentos, destaccando-se [sic] roupas e jóias da época africana, notadamente o tear de "pano da costa", o qual tem uma história especial. (A Tarde, 10 nov. 1955 grifos nossos)

O tripé raiz-arte-popular, então sustentáculo da brasilidade (e da cultura baiana) e, neste caso, do colecionismo, são grandezas ativas no IFB e em quem formou a coleção e o Museu, compactuando com o 'povo' pormenorizado nas descrições. Mais uma vez pela modelagem narrativa e a da adjetivação, a confirmação para legitimar os "pequenos nadas", como se pode ler a seguir:

Não foi sem razão [que se formou o Museu], pois que o Instituto Feminino da Bahia abriu suas portas satisfeito, especialmente para mostrar aos participantes do 3 은 Congresso Nacional de Folclore o Museu de Arte Popular. Isso porque, de longa data, guarda com carinho êsses pequenos nadas, que se expõem nas feiras e nos mercados, neles sentindo a alma simples do artista anônimo, sempre igual e fiel à sua arte ingênua. (ALVES, 1959, grifo nosso)

Em um só parágrafo o motivo para formar o conjunto de peças populares e o museu pautados, primeiro, no apreço e afeto (guardar com carinho), o atestado que o colecionismo do IFB começara muito antes do movimento dos folcloristas, e a posição social do produtor desconhecido, sujeito a certa imutabilidade (fiel à sua arte): o guardião de tradições e, possivelmente, pobre (que vive da arte em feiras e mercados).

\section{Em defesa das tradições: o}

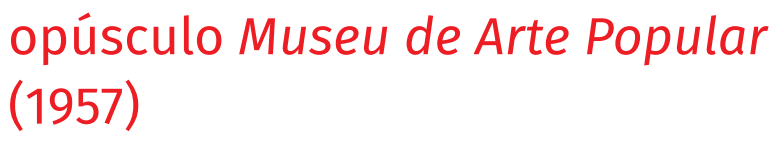

No momento em que a relevância da cultura popular e das tradições que, mesmo posteriormente, eram apreendidas como estrutura da sociedade brasileira (TOURINHO, 1961, p. 69), o IFB abriu as portas para o III Congresso Nacional de Folclore, realizado em 1957. O opúsculo Museu de Arte Popular (03 de julho), contribuição do IFB para o evento, confirma a defesa do passado, das tradições e da cultura popular.

Os opúsculos, muitos de autoria de Marieta Alves, que acompanhavam as exposições temporárias, refletem mais diretamente a filosofia do IFB, distinguindo-se das notícias de jornais que, de certo modo, a repetiam. Para a pergunta registrada se o folclore era ou não ciência, a resposta afirmativa - "ciência do povo, mas nem por isso menos digna" - evidencia que o Instituto conhecia os embates pelos quais lutavam os folcloristas. Por sua vez, o Instituto esperava, com a participação no evento, que o material exposto no subsolo alcançasse autonomia, melhores instalações, biblioteca especializada, elaboração de catálogo, de modo a cumprir o papel educativo que cabia aos museus (MUSEU DE ARTE POPULAR, 1957, p. 5-6).

$\mathrm{Na}$ pequena publicação (cinco páginas de texto) a condensação do discurso e diretrizes institucionais. Nela o realce para a manutenção da História, da Arte e Tradição e a defesa do reviver educativo das festas populares (Ternos de Reis; Bumba meu boi; São João), na contramão das influências negativas a que as crianças estavam expostas - revistas em quadrinhos, cinema impróprio para a idade, futebol, excessivas idas à praia - causas do desaparecimento de cantigas de roda e histórias narradas pelas avós. Pode-se dizer que aí a expressão da "pedagogia civilizatória", explicitada por Renato Ortiz (1992, p. 36-39), ao se 
referir aos embates entre românticos e folcloristas, ambos da tradição. 0 perceptivel tom nostálgico reflete o descontentamento pelo desvio de costumes e o choque entre o passado (de valor positivo) e o modernizante (negativo), pondo em risco a perda das tradições, posicionamento que se afina ao espírito elitista e conservador observado na pesquisa de Elizete Silva Passos (1993, p. 18) ao comentar a natureza do movimento feminino na Bahia e do IFB.

O impresso na voz de Marieta Alves, igualmente voz do IFB demonstra, explicitamente, valores ali priorizados: o desejo de Henriqueta de ficar nos bastidores ao referendar os 33 anos dedicados pela Diretoria à educação (e não a ela diretamente), e a vontade de garantir a presença da Bahia no popular nacional através do artesão - a "alma" da "chama do ideal", executor do "típic[o] de nossa terra" -. Patrimônio digno de preservação reforçado nas frases finais do opúsculo, firmando o pacto de salvaguarda do popular.

\section{Fechando: o colecionismo de dois mundos}

Com efeito, os museus do Instituto Feminino da Bahia ficaram conhecidos, apreciados e requisitados exibindo a Bahia para o Brasil menos com ditames científicos e mais pela função educativa apoiada no ver para aprender através dos museus e exposições. É de se notar o contraste não somente de matérias-primas entre os exemplares representativos da elite do passado e do universo feminino aristocrático, apresentados nas exposições de longa duração ou temporárias, com os artefatos populares, incluindo peças do Candomblé no Museu de Arte Popular. $O$ embate de forças simbólicas de dois mundos separados pela ocupação de espaços sociais distintos, como explica Pierre Bourdieu (2007), fica a cargo do dito (ou expos- to), apagando outros sentidos (ORLANDI, 2001).

Não obstante o enquadramento crítico no encalço da colecionista Henriqueta, é preciso reconhecer que o amealhado nos museus mantidos pelo FIFB contribui - agora em outra perspectiva - para a investigação sobre o patrimônio cultural baiano mediante manifestações museológicas. As fontes consultadas levam a crer que a expressão do seu lado colecionista ficou encoberta pelas intenções enraizadas na formação, na fé católica, na filosofia de vida caritativa, na determinação e no desejo de ajudar ao próximo, em missão que abraçou durante sua jornada com apoio da Igreja, prática sustentada graças à posição social de destaque conquistada por ela e pela instituição, construindo o arco de ligação entre redes sociais em oposição - a da elite e a do popular.

\section{Referências}

ALVES, Elder Patrick Maia. O movimento folclórico brasileiro: guerras intelectuais e militância cultural entre os anos de 50 e 60. Desigualdade \& Diversidade. Revista de Ciências Sociais, PUC-RIO, n. 12, p. 131-152, jan./dez., 2013. Disponivel em: http://desigualdadediversidade.soc.puc-rio.br/media/11\%20 -\%20artigo\%207\%20-\%20Elder\%20Alves.pdf. Acesso em: 19 set. 2019.

ALVES, Marieta. Henriqueta Martins Catharino: sua vida e sua obra. In: Museu do Traje e do Têxtil. Salvador: Fundação Instituto Feminino da Bahia, 2003, p. 17-23.

As Victorias do Instituto Feminino. Trabalhos artísticos expostos. A Tarde. Salvador, p. 3, 06 ago.1932.

Belezas do mar. Exposição anual do Instituto Feminino. A Tarde, p. 2, 05 out. 1956.

BETTENCOURT, Gastão de. 0 Folclore no Brasil. Salvador: Publicações da Universidade da Bahia/Brasil, 1957.

BOURDIEU, Pierre. A Distinção. Crítica social do julgamento. São Paulo: EDUSP: Porto Alegre, RS: Zouk, 2007. 
BRITTO, Clovis Carvalho. Gramática expositiva das coisas. A poética alquímica dos museus-casas de Cora Coralina e Maria Bonita. Salvador: EDUFBA, 2018.

BRITTO, Clovis Carvalho. Museus e Acervos Literários: a experiência dos 'papéis de circunstância' no Museu-Casa de Cora Coralina em Goiás-GO. Musas (IPHAN), Brasília, v. 6, p. 164-181, 2014. Disponivel em: http://www.museologia.fci.unb.br/ component/phocadownload/file/89-britto-cloviscarvalho-museus-e-acervos-literarios-a-experiencia-dos-papeis-de-circunstancia-no-museu-casa-de-cora-coralina-em-goias-go-musas-iphan-v6-p-164-181-2014. Acesso em: 19 set. 2019.

CHAVES, Wagner Neves Diniz. Identidade, narrativa e emoção no Museu Théo Brandão de Antropologia e Folclore. ANTHROPOLÓGICAS, PPGA UFPE, ano 16, vol. 23(2), p. 50-97, 2012. Disponivel em: https:// periodicos.ufpe.br.revistaanthropologicas.article. download. Acesso em: 19 set. 2019.

CERÁVOLO, Suely Moraes. Exposições Temporárias para as "Senhoras e Senhoritas" da sociedade baiana: o discurso performativo do Instituto Feminino da Bahia (1920 a 1968). V Congresso Sergipano de História/V Encontro Estadual de História ANPUH/ Sergipe, 2016, Aracaju. Anais [eletrônicos] V Congresso Sergipano de História/V Encontro Estadual de História ANPUH/Sergipe, Aracaju, ANPUH/Sergipe, 2016. Disponivel em: http://www.encontro2016. se.anpuh.org/resources/anais/53/1486583730_ARQUIVO_1472552711_ARQUIVO_CERAVOLOANPUHrevisto08.016k.pdf. Acesso em: 19 set. 2019.

CERÁVOLO, Suely Moraes. Colecionando "homens e cousas": por um perfil do Museu do Instituto Geográfico e Histórico da Bahia (1894-1927). Revista do IGHB, Salvador, v. 112, p. 97-134, 2017.

COSTA, Paulo de Freitas. Sinfonia de objetos. A coleção de Ema Gordon Klabin. São Paulo: Iluminuras, 2007.

COUTINHO, Paula Andrade. Do palacete ao castelo: estudo da trajetória do colecionador Henry Joseph Lynch. 2018, 151 f. Dissertação (Mestrado em Filosofia). Faculdade de Filosofia e Ciências Humanas, Universidade Federal da Bahia, Salvador. Disponível em: http://www.repositorio.ufba.br:8080/ri/handle/ri/25338. Acesso em: 19 set. 2019.

CUNHA, Marcelo Bernardo Nascimento da. Teatro de memórias, palco de esquecimentos: culturas africanas e das diásporas negras em exposições. 2006. 295 f. Tese (Doutorado em História). Pontifícia Universidade Católica de São Paulo, São Paulo, 2006. Disponivel em: http://www.museologia.ffch.ufba. $\mathrm{br} / \mathrm{sites} / \mathrm{museologia.ffch.ufba.br/files/tese \_ mar-}$ celo_nascimento_bernardo_da_cunha.pdf. Acesso em: 19 set. 2019.

DEAN, Carolyn. The trouble with (The Term) Art. Art Journal, College Art Association, v. 65, n. 2, p. 24-32, Summer, 2006. Disponivel em: https://www.bucknell.edu/documents/griotinstitute/deanarticle.pdf. Acesso em: 19 set. 2019.

DIAS, Carla da Costa. De sertaneja à folclórica, a trajetória das coleções regionais do Museu Nacional (1920-1950). 2005. 251f. Tese (Doutorado em Artes Visuais) - Programa de Pós-graduação em Artes Visuais, Universidade Federal do Rio de Janeiro, Rio de Janeiro, 2005. Disponivel em: https://pantheon. ufrj.br/bitstream/11422/5494/1/719925.pdf. Acesso em: 19 set. 2019.

Exposição de Arte Antiga. A Tarde, p. 10, 28 mar. 1949.

Exposição de louças e porcelanas antigas. A Tarde, p. 5, 13 jul. 1955.

Exposição comemorativa do 33으 aniversário IFB. A Tarde, p. 3, 05 out. 1956.

Faziam flores de penas para viver! Interessantes trabalhos das freiras Ursulinas em tempos dificeis. Esculturas em madeira. 0 que vimos no museu do Instituto Feminino. Estado da Bahia. 18 ago. 1941.

FLORES, Joana. Mulheres negras e museus de Salvador: diálogo em branco e preto. Salvador: EDUFBA, 2017.

GUTIERREZ, Angela. Coleções - entre o público e o privado. In: MAGALHÃES, Aline Montenegro; BEZERRA, Rafael Zamorano. Coleções e Colecionadores. A polissemia das práticas. Rio de Janeiro: Museu Histórico Nacional, 2012, p. 254-257.

HOLLANDA, Guy de. Recursos Educativos dos Mu- 
seus Brasileiros. Rio de Janeiro: Centro Brasileiro de Pesquisas Educacionais: Organização Nacional do ICOM, 1958.

LOPES, Telê Porto Ancona. Viagens Etnográficas de Mário de Andrade: Itinerário Fotográfico. Revista do IEB, Instituto de Estudos Brasileiros/USP, n. 11, p. 139174, 1972. Disponível em https:/ / www.revistas.usp.br/ rieb/issue/view/5542. Acesso em: 19 set. 2019.

MENESES, Ulpiano T. Bezerra. Do teatro da memória ao laboratório da História: a exposição museológica e o conhecimento histórico. Anais do Museu Paulista, Universidade de São Paulo, Nova Série, v. 2, p. 9-42, 1994. Disponivel em: http://www.scielo.br/pdf/ anaismp/v2n1/a02v2n1.pdf. Acesso em: 19 set. 2019.

Museu de Arte Popular. Instituto Feminino da Bahia: Instituto Feminino da Bahia, 1957.

Museu Regional de Arte Antiga. O Imparcial, p. 2, 24 set. 1938.

O Aniversário de uma útil instituição. Exposição de arte e festa de amizade no Instituto Feminino. A Tarde, Salvador, s/p , 01 out. 1941.

O Apostolado do Bem e da Virtude. Como se forma o coração e o espírito da mulher - O Instituto Feminino da Bahia - Seus elogiáveis fins e excelentes programas. 0 Imparcial, s/p, 13 jun. 1932.

OLIVEIRA, Ana Karina Rocha de. Museologia e Ciência da Informação: distinções e encontro entre áreas a partir da documentação de um conjunto de peças de 'roupas brancas'. 2009. 133 f. Dissertação (Mestrado em Comunicação). Escola de Comunicação e Artes/USP, Universidade de São Paulo, São Paulo. Disponivel em: http://www.teses.usp.br/ teses/disponiveis/27/27151/tde-27102009-002603/ pt-br.php. Acesso em: 19 set. 2019.

ORLANDI, Eni Puccinelli. Discurso e Texto: formação e circulação de sentidos. Campinas, SP: Pontes, 2001.

ORTIZ, Renato. Românticos e Folcloristas. Cultura Popular. São Paulo: Editora Olho d'Água, 1992.

PASSOS, Elizete Silva. Henriqueta Catharino. Salvador: EDUFBA/FACED, 2010.
PASSOS, Elizete Silva. Mulheres moralmente fortes. Salvador: Gráfica Santa Helena, 1993.

PEIXOTO, Ana Lúcia Uchoa. O Museu do Traje e do Têxtil. In: Museu do Traje e do Têxtil. Salvador: Fundação Instituto Feminino da Bahia, 2003. p. 11-15.

PEREIRA, Juliano Aparecido. A ação cultural de Lina Bo Bardi na Bahia e no Nordeste (1958-1964). Dissertação (Mestrado em Engenharia). 2001, 305 f. Escola de Engenharia de São Carlos, Universidade de São Paulo, 2001.

QUEIRÓZ, Marijara Sousa. Museu, memória e morte. Um estudo a partir da coleção de quadros de cabelos da Fundação do Instituto Feminino da Bahia. 2014, 128 f. Dissertação. (Mestrado em Artes). Escola de Belas Artes, Universidade Federal da Bahia, Salvador.

QUEIRÓZ, Marijara Sousa. De escola para mulheres a museu feminino: o colecionismo de Henriqueta Martins Catharino. In: Seminário Nacional de História da Ciência e da Tecnologia, Florianópolis, Santa Catarina. Anais [eletrônicos] 15o Seminário Nacional de História da Ciência e da Tecnologia, Sociedade Brasileira de História das Ciências, 2016. Disponível em: https:/ / www.15snhct.sbhc.org.br/resources/ anais/12/1474401190arquivodatosmarijaraadjuntossintitulo02410.pdf. Acesso em: 09 out. 2019

ROMO, Anadelia. Writing Bahian Identity: Crafting New Narratives of Blackness in Salvador, Brazil, 1940-1950. Journal of Latin American Studies, Cambridge University Press, v. 50, n. 4, p. 805-832, 2018.

SANTOS, Jancileide Souza de. Colecionadores e Colecionismo de Arte Popular na Bahia. XI EHA - Encontro de História da Arte. Da percepção à palavra: luz e cor na História da Arte, Campinas, Unicamp, Anais [eletrônicos] Centro de História da Arte e Arqueologia, 2015, p.234-239. Disponivel em: https:// www.ifch.unicamp.br/eha/atas/2015/Jancileide\%20 Souza\%20dos\%20Santos\%20.pdf. Acesso em: 09 out. 2019.

SILVA, Armando. Álbum de família: a imagem de nós mesmos. São Paulo: Editora Senac SP; Edições SESC-SP, 2008.

SOARES, Lélia Gontijo. Mário de Andrade e o Folclo- 
re. In. Departamento de Cultura da Prefeitura do Município de São Paulo 1936-1939. Mário de Andrade e a Sociedade de Etnografia e Folclore. Rio de Janeiro: FUNARTE, Instituto Nacional de Folclore; São Paulo: Secretaria Municipal de Cultura, 1983, p. 7-14.

SOUZA, Jean Costa. "O Culto à Tradição de nossa gente": a fabricação do Folclore Sergipano em exposições museológicas (1948-1976). 2019. 157 f. Dissertação. Programa de Pós-graduação Interdisciplinar em Culturas Populares, Fundação Universidade Federal de Sergipe, Aracaju, 2019.

TOURINHO, Antonio C. Estudo sobre o Turismo. Salvador: Imprensa Oficial da Bahia, 1961.

Uma exposição no Instituto Feminino. A Tarde, p. 3, 11 out. 1941.

VALE, Renilda Santos do. Memória da fé: a coleção de paramentos litúrgicos do Museu do Traje e do Têxtil da Fundação Instituto Feminino da Bahia.
2017. 229 f. Dissertação (Mestrado em Filosofia) Faculdade de Filosofia e Ciências Humanas, Universidade Federal da Bahia, Salvador. Disponível em: https://repositorio.ufba.br/ri/handle/ri/22657. Acesso em: 05 nov. 2019

VERÓN, Eliseo. Fragmentos de um tecido. São Leopoldo, RS: Editora da Universidade do Vale do Rio dos Sinos, 2004.

VIEIRA, Claudia Andrade. História das Mulheres: feminismo e política na Bahia. Simões Filho: Editora Kalango, 2015.

VILHENA, Luís Rodolfo. Projeto e missão. O movimento folclórico brasileiro 1974-1964. Rio de Janeiro: Funaerte; Fundação Getúlio Vargas, 1997.
Recebido em: 23.12.2019 Revisado em: 27.04 .2020 Aprovado em: 03.05.2020

Suely Moraes Cerávolo é Doutora em Ciências da Comunicação pela Universidade de São Paulo. Professora da Universidade Federal da Bahia. Líder do Grupo de Pesquisa Observatório da Museologia na Bahia. E-mail: sumocem@gmail.com. 